NIST Technical Note 2025

\title{
Intelligent Building Agents Laboratory: Air System Design
}

Dr. Amanda J. Pertzborn

Dr. Daniel A. Veronica

This publication is available free of charge from:

https://doi.org/10.6028/NIST.TN.2025

National Institute of Standards and Technology

U.S. Department of Commerce 
NIST Technical Note 2025

\title{
Intelligent Building Agents Laboratory: Air System Design
}

\author{
Dr. Amanda J. Pertzborn \\ Engineering Laboratory \\ Energy and Environment Division \\ Mechanical Systems \& Controls \\ Dr. Daniel A. Veronica \\ Engineering Laboratory \\ Energy and Environment Division \\ Mechanical Systems \& Controls
}

This publication is available free of charge from:

https://doi.org/10.6028/NIST.TN.2025

September 2018

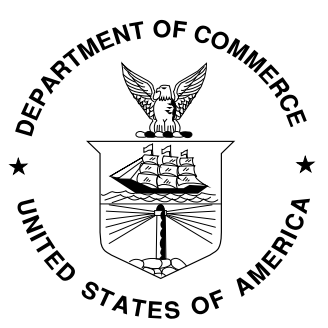

U.S. Department of Commerce Wilbur L. Ross, Jr., Secretary

National Institute of Standards and Technology Walter Copan, NIST Director and Undersecretary of Commerce for Standards and Technology 
Certain commercial entities, equipment, or materials may be identified in this document in order to describe an experimental procedure or concept adequately. Such identification is not intended to imply recommendation or endorsement by the National Institute of Standards and Technology, nor is it intended to imply that the entities, materials, or equipment are necessarily the best available for the purpose.

National Institute of Standards and Technology Technical Note 2025 Natl. Inst. Stand. Technol. Tech. Note 2025, 35 pages (September 2018) CODEN: NTNOEF

This publication is available free of charge from: https://doi.org/10.6028/NIST.TN.2025 


\begin{abstract}
The National Institute of Standards and Technology has constructed the Intelligent Building Agents Laboratory (IBAL) to demonstrate the potential for distributed, intelligent software agents to optimize the control of heating, ventilation, and air-conditioning systems in commercial buildings. The goal of the optimization is to improve the economic and energy performance of building systems while maintaining occupant comfort. This paper describes the design of, and the equipment in, the airside system of the IBAL.
\end{abstract}




\section{Acknowledgements}

The wiring, instrumentation, and data rack design of the laboratory are primarily the efforts of Glen Glaeser. Glen contributed significantly to bringing the laboratory online. Cynthia Hudson oversaw the construction and liased with the contractor regarding the design. We also thank former Summer Undergraduate Research Fellows (SURF) students Nusrat Molla, Philip Hoddinott, and Thomas Lacey for the work they completed during the summers of 2015, 2016, and 2017, respectively. Harrison Skye assisted in brainstorming parts of the LabVIEW code and was a sounding board for uncertainty calculations, as was James Yen. Gregory Cala also consulted on the design of the LabVIEW code. Farhad Omar, W. Vance Payne, and Mark Kedzierski all aided in solving problems that arose during commissioning. Arthur E. Ellison and Luis Luyo assisted at various points installing instrumentation and wiring in the lab. John Allen Wamsley assisted in some of the challenging plumbing work and consulted on various heating, ventilation, and air-conditioning troubleshooting issues. Finally, we would like to thank the reviewers of this document, Steven Bushby, Dhananjay Anand, and Gregory Linteris for their feedback and suggestions. 


\section{Table of Contents}

Nomenclature ............................................................................................................................. vi

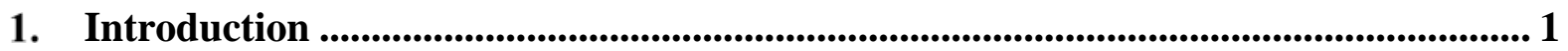

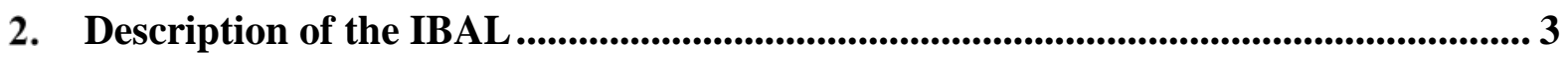

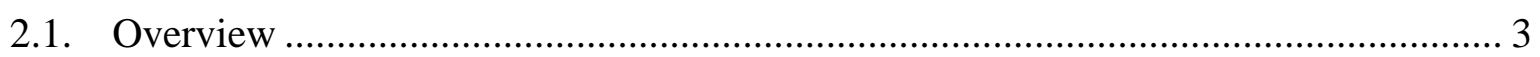

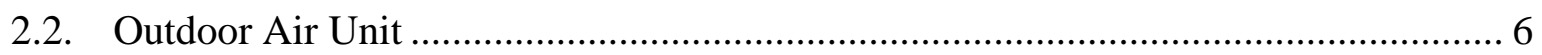

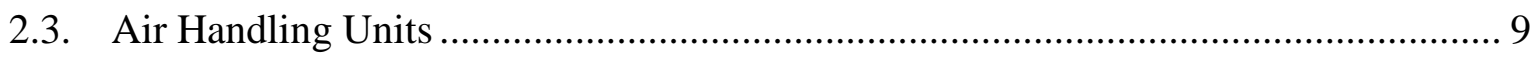

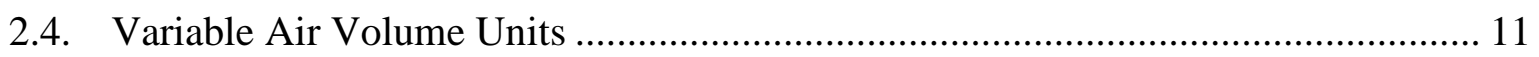

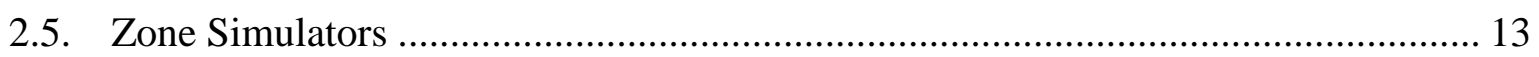

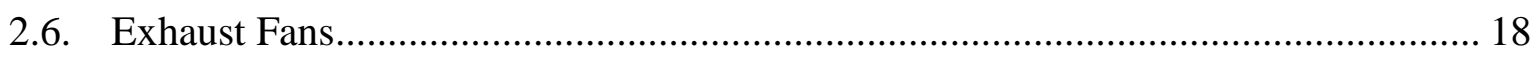

3. Data Collection and Operation........................................................................................ 18

4. Measurement Uncertainty Calculations............................................................................. 18

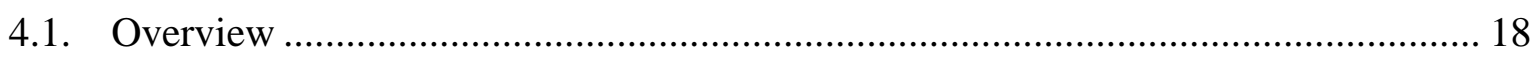

4.2. Uncertainty of Calibration Curve Fit.................................................................. 19

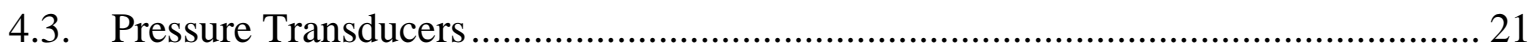

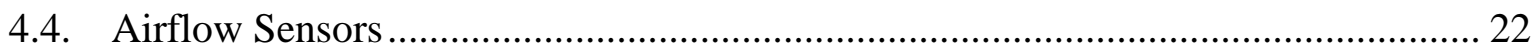

4.5. Relative Humidity Sensors ............................................................................... 23

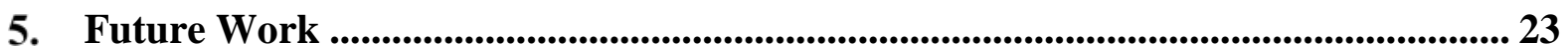

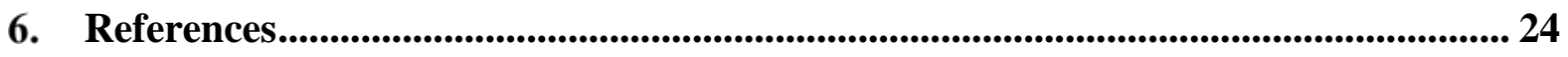

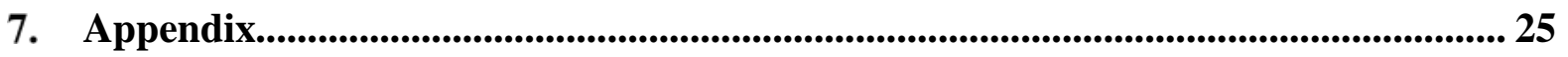




\section{List of Tables}

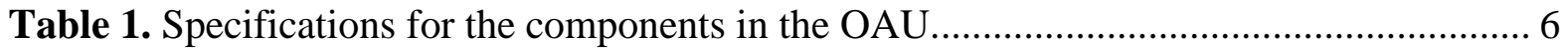

Table 2. Specifications for the components in the AHU............................................... 9

Table 3. Loads for Case 1: open office space. .................................................................. 15

Table 4. Loads for Case 2: conference room. ................................................................ 16

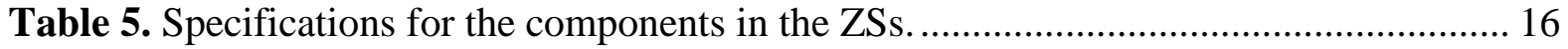

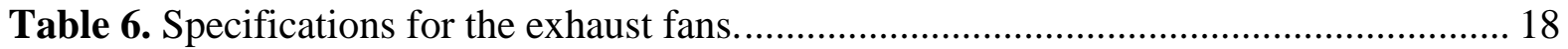

Table 7. Uncertainties of temperature, voltage, and current measurements of DAQ hardware.

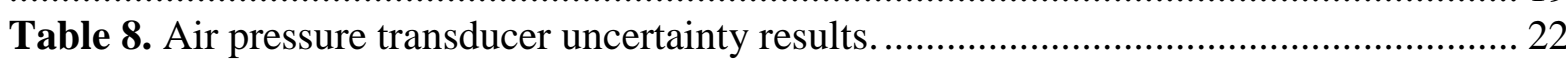

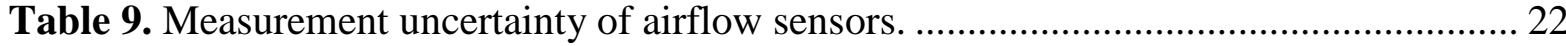

Table 10. Measurement uncertainty of airflow sensors. ................................................ 22

Table 11. Measurement uncertainty and calibration fit for RH sensors............................. 23

Table 12. Summary of sensors in the air system in the IBAL. ........................................ 25

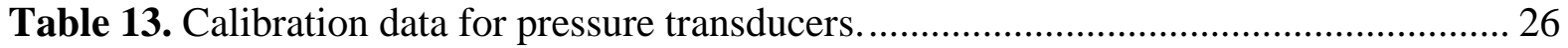

Table 14. Calibration data for relative humidity sensors. ............................................... 26 


\section{List of Figures}

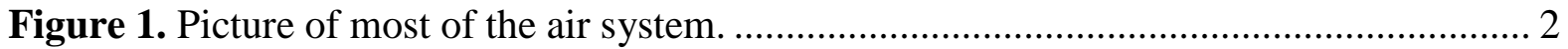

Figure 2. Picture of most of the water system................................................................ 3

Figure 3. Schematic of the IBAL air system. The dashed lines indicate a boundary between

the interior and exterior of the building. ......................................................................... 5

Figure 4. Legend for the component schematics. ...................................................... 7

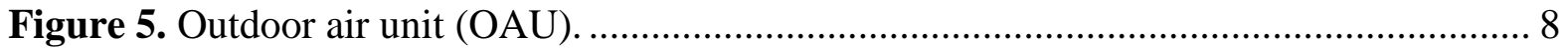

Figure 6. Picture of the OAU. Air is drawn in from the left, exits the OAU on the top left of the unit, and goes to the AHUs at the right (not shown) ............................................... 9

Figure 7. Air Handling Units (AHUs). See Figure 4 for the legend................................... 10

Figure 8. AHU2 (top) and AHU1 (bottom). The OAU is on the upper mezzanine at the far left of the picture and the VAVs, not shown, are to the right............................................ 11

Figure 9. Variable air volume boxes (VAV). See Figure 4 for the legend. ......................... 12

Figure 10. Picture of the VAVs. The AHUs are to the left and the ZSs are to the right. ...... 13

Figure 11. Zone simulators (ZS). See Figure 4 for the legend.......................................... 14

Figure 12. Picture of the four ZSs. The VAVs are at the left. .......................................... 15

Figure 13. The black tanks hold water for the thermal mass coils in the zone simulators. Above the tanks are the red circulating pumps that move the water through the TMCs. The flow rate is determined by manually setting a valve.

Figure 14. Picture of the air pressure calibration setup. The precision pressure controller is at the far left and two pressure transducers (the gray boxes) are visible. 


\section{Nomenclature}

a calibration constant

b intercept

$m$ slope

$n \quad$ number of data points

$s \quad$ standard deviation

se standard error

$t$

$u$

$x$

$y$

AHU

AI

$\mathrm{AO}$

CC

EXF

IBAL

OAU

$\mathrm{P} / \mathrm{N}$

$\mathrm{RH}$

$\mathrm{S}$

SCR

$\mathrm{S} / \mathrm{N}$

SS

$\mathrm{SSH}$

SSResid

TMC

VAV

ZS value of the Student t-test

uncertainty

independent variable

dependent variable

air-handling unit

analog input

analog output

cooling coil

exhaust fan

Intelligent Building Agents

Laboratory

outdoor air unit

part number

relative humidity

value used in calculating a

linear curve fit

silicon-controlled rectifier

serial number

sum of squares

steam spray humidifier

sum of the square of residuals

thermal mass coil

variable air volume

zone simulator

\section{Subscripts}

0

1 term in the calibration curve

fit

d downstream

e expanded

r residual

total calculated from all results

$\mathrm{u}$

$\mathrm{xx} \quad$ term using only independent variable

xy term using the independent and dependent variables

\section{Other symbols}

$\bar{x} \quad$ mean of " $\mathrm{x}$ "

$\hat{x} \quad$ value of " $\mathrm{x}$ " from a curve fit

$v \quad$ degrees of freedom 


\section{Introduction}

Achieving national goals of net zero energy buildings requires substantial reduction in the energy consumption of commercial building systems. In 2017, commercial buildings consumed $18 \%$ of the total energy consumed in the U.S. [1]. Although significant progress has been made in the integration of building control systems through the development of standard communication protocols, such as BACnet and BACnet/IP, little progress has been made in making them "intelligent" about optimizing building system-level performance. The focus of this project is to demonstrate the potential for distributed, intelligent software agents to perform this optimization. That focus required designing and building a research infrastructure suitable for development and testing of advanced agent-based optimization techniques to improve the energy and comfort performance of heating, ventilating, and air conditioning (HVAC) systems in buildings.

An intelligent agent can take many forms, but the basic concept is that it acquires information about the state of the system, makes an optimal or near-optimal control decision, and communicates that decision to another agent or to an actuator that executes the decision. The agent can represent a piece of HVAC equipment such as an air-handling unit (AHU) and learn how that AHU operates over time to produce an optimal or near-optimal operating point given the current or forecast system conditions. An HVAC system would contain multiple agents that communicate to make choreographed control decisions that lead to optimal or near-optimal operation of the overall system. In this way the decision-making process is distributed.

Kelly and Bushby [2] completed a feasibility study to determine if intelligent agent technology could lead to significant savings in HVAC energy consumption. Their study was comprised of 17 agents:

- 8 - VAV (variable air volume) agents

- 2 - AHU agents

- 2 - Chiller agents

- 2 - Cooling tower agents

- 1 - Agent to coordinate the actions of the other agents

- 1 - Agent to quantify the operating cost of the system

- 1 - Agent to control the simulation

To simulate the learning that an agent would have to do in the real world to understand how a given piece of equipment operates, models of each HVAC component were developed and used to provide data to the agent under a variety of conditions. Regression models were developed based on the data and these models were incorporated into the agents to predict equipment performance. With the agents now capable of estimating the performance of their equipment, the next step was to develop a method to optimize system performance.

Kelly and Bushby tested two methods, a simple optimization method (SOM) and an advanced optimization method (AOM). Only the SOM will be presented here because the 
AOM did not lead to a significant increase in savings relative to SOM. In SOM, the HVAC agents take turns optimizing the operation of their equipment. The optimal operation of one piece of equipment often conflicts with the optimal operation of another piece of equipment. For example, the AHU may have optimal performance when the chiller provides it with water at $1.7^{\circ} \mathrm{C}\left(35^{\circ} \mathrm{F}\right)$, but the chiller may have better performance producing water at 12.8 ${ }^{\circ} \mathrm{C}\left(55^{\circ} \mathrm{F}\right)$. In each time step, one agent determines how it would like to operate its equipment, calculates the cost of that operation, and communicates with the other agents to determine what the impact of that operation is on the other equipment in the system and the overall system cost. The agent can then decide if, given the overall impact on the system, it should change its set point as proposed. In the next time step, a different agent leads this process.

Kelly and Bushby [2] showed that, in a simulation of a single day of operation, the cost savings over a reference case without optimization was $21 \%$. Although the authors note that these savings are dependent on the details of the reference case, this proof of concept study was promising enough to justify the construction of a laboratory to test the concept using actual HVAC equipment. The Intelligent Building Agents Laboratory (IBAL) is the culmination of that effort. The IBAL contains an air system able to emulate those typically found in commercial buildings and a hydronic system able to emulate a variety of designs typical of their plants. The IBAL is capable of representing a building having a modern, efficient HVAC system, or a building constrained by an older, more obsolescent design.

The air system is located on a mezzanine (see Figure 1) and the hydronic system is located underneath the mezzanine (see Figure 2). There is an AHU dedicated to conditioning outdoor air to produce repeatable test conditions and zone simulators to emulate building loads. All of the equipment are monitored and controlled from a central data acquisition (DAQ) system. This technical note will describe the design and construction of the air system; Pertzborn [3] described the hydronic system in detail.

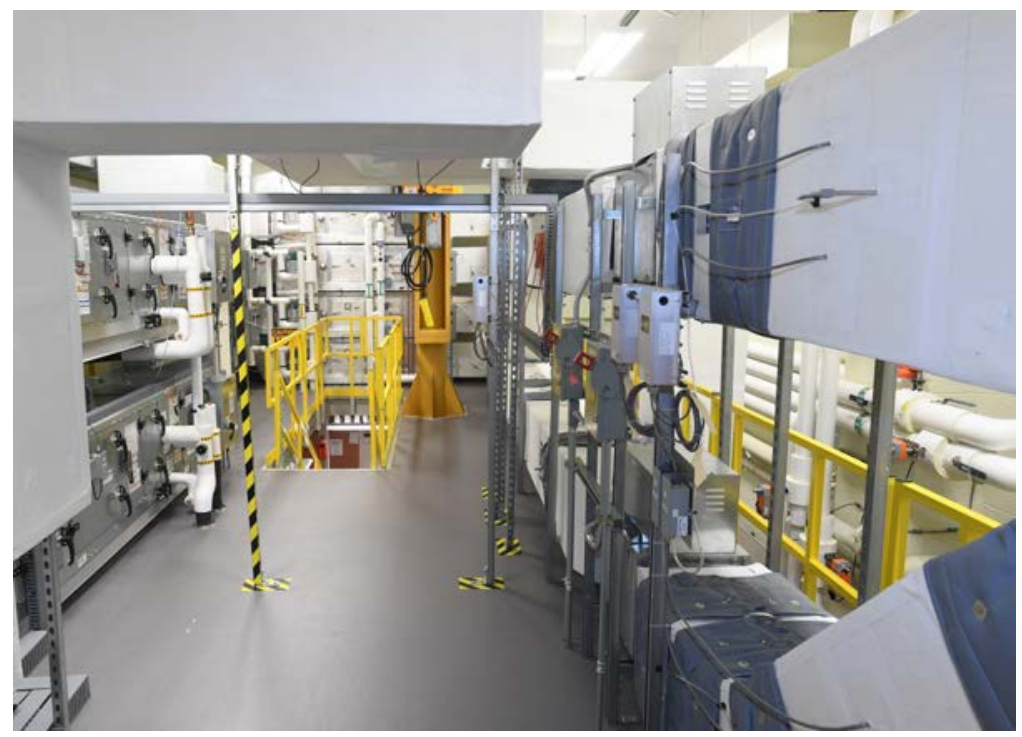

Figure 1. Picture of most of the air system. 


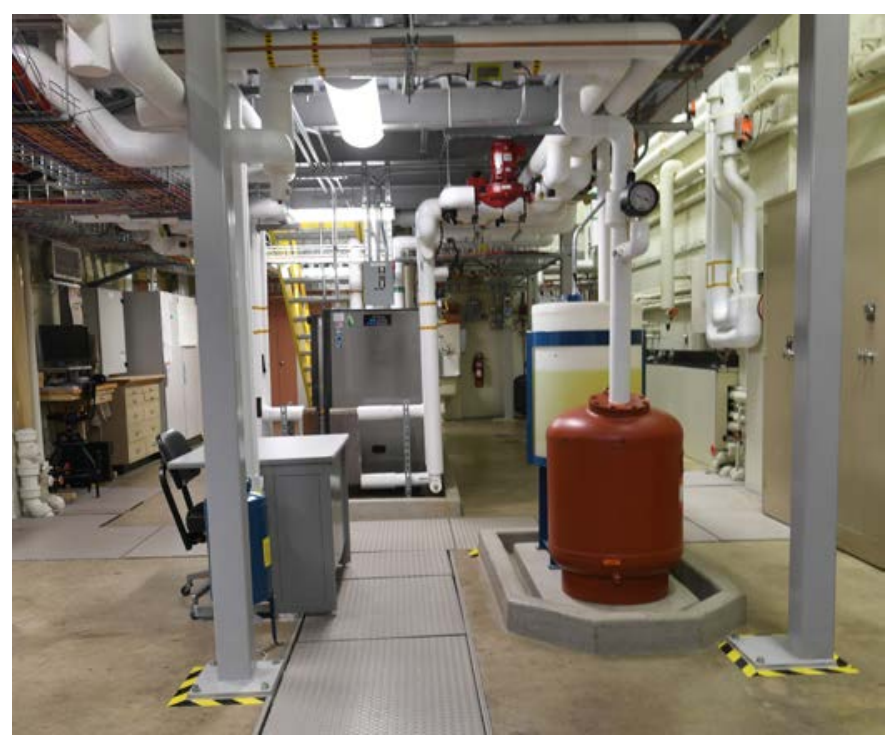

Figure 2. Picture of most of the hydronic system.

\section{Description of the IBAL}

The purpose of the IBAL is to emulate a small office building in terms of the complexity and the type of HVAC systems and equipment that would typically be present. Since the primary use of the facility is conducting consistently controlled experiments that characterize the performance of a wide variety of intelligent control algorithms, system design decisions and equipment selections were made to allow as many control options as possible. This section will describe the mechanical design of the air system of the IBAL in detail.

\subsection{Overview}

The IBAL contains the following equipment:

- Air system

o 1 - Outdoor air unit (see Sec. 2.2)

o 2 - Air handling units (see Sec. 2.3)

o 4 - Variable air volume units (see Sec. 2.4)

o 4-Zone simulators (see Sec. 2.5)

o 2 - Exhaust fans (see Sec. 2.6)

- Hydronic system
o 2 - Chillers
o 1 - Thermal storage tank
o 3 - Heat exchangers

This technical note will describe the air system, shown in Figure 3. Later sections will discuss and show each component in more detail. At the far left is the outdoor air unit (OAU). This component conditions the actual outdoor air to provide the simulated outdoor air conditions for each test, which allows the same test to be repeated on different days. The 
OAU provides simulated outdoor air to two AHUs, which condition the simulated outdoor and return air to meet the needs of the four zones. The cooling coils in the AHUs use a $30 \%$ propylene glycol (PG) mixture from the chillers to cool and dehumidify the air. The system is nominally designed so that a single AHU serves two zones, and the variable air volume (VAV) units are used to modify the air temperature and/or flow rate to meet the needs of the individual zone. However, dampers D9 and D12 (see Figure 3) can be opened to allow one AHU to serve more than two zones. The four zone simulators (ZSs) provide a load for the system and the exhaust fans (EXFs) are used to reject air outside of the building. 


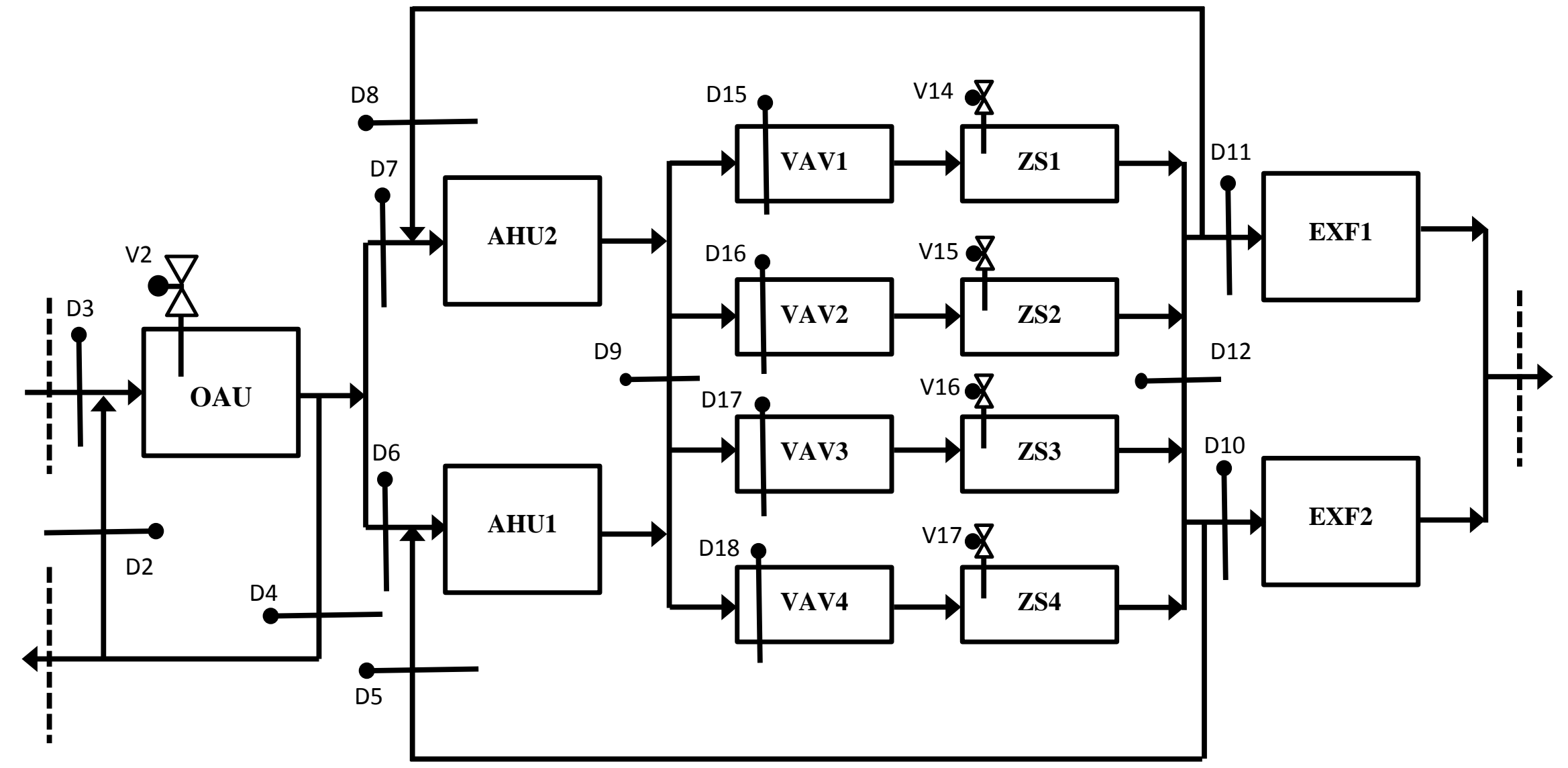

Figure 3. Schematic of the IBAL air system. 


\subsection{Outdoor Air Unit}

The OAU conditions outside air to simulate weather conditions for laboratory testing. The independent regulation of both the temperature and humidity of the air being supplied by the OAU is essential to the creation of relevant and repeatable test scenarios. The appropriate design for the OAU is thus one following the concept of a "single-zone" air system as described by Lorsch in [4]; here the single "zone" is a continual flow of air supplied as if drawn in from outside at a specified "outdoor" condition. Figure 4 is the legend for Figure 5, which shows the components of the OAU and the installed sensors/controls.

The cooling coil (CC) of the OAU regulates the dewpoint of this "outdoor" airflow and/or lowers the dry-bulb temperature, while the internal electric reheat element independently regulates its temperature. The steam spray humidifier (SSH) provides humidification capability in case ambient conditions require raising the dewpoint to an experiment's specification instead of lowering it. The OAU, along with ductwork giving it an inlet and an outlet to the real outdoors, creates a circulating flow of treated air whose flowrate can be maintained independent from the amount of air drawn in by the AHUs. The fan is connected to a variable frequency drive (VFD) that allows it to operate over a range of flow rates.

These components work together to provide the desired temperature and humidity at the outlet of the OAU as measured by T86 and RH351 (see Figure 5), respectively. The specifications for each component are given in Table 1 and Figure 6 is a picture of the OAU.

Table 1. Specifications for the components in the OAU.

\begin{tabular}{l|l|l} 
Component & Description & Value \\
\hline Cooling coil & Refrigerant & R410A \\
& Total capacity & $68 \mathrm{~kW}(20 \mathrm{tons})$ \\
\hline Electric heater & Capacity & $60 \mathrm{~kW}$ \\
& SSR controller & $(0$ to 10$) \mathrm{V}$ \\
\hline Steam spray humidifier & Steam pressure & $34.5 \mathrm{kPa}(15 \mathrm{psig})$ \\
& Steam rate & $30 \mathrm{~kg} / \mathrm{h}(67 \mathrm{lbm} / \mathrm{h})$ \\
& Steam rate control via V2 & $(2$ to 10$) \mathrm{V}$ \\
\hline Fan & Maximum airflow & $4757 \mathrm{~m} / \mathrm{h}(2800 \mathrm{cfm})$ \\
& Maximum speed & $163 \mathrm{rad} / \mathrm{s}(1558 \mathrm{rpm})$ \\
& Total static pressure & $708 \mathrm{~Pa}(2.8 \mathrm{inH} \mathrm{O})$ \\
\hline
\end{tabular}




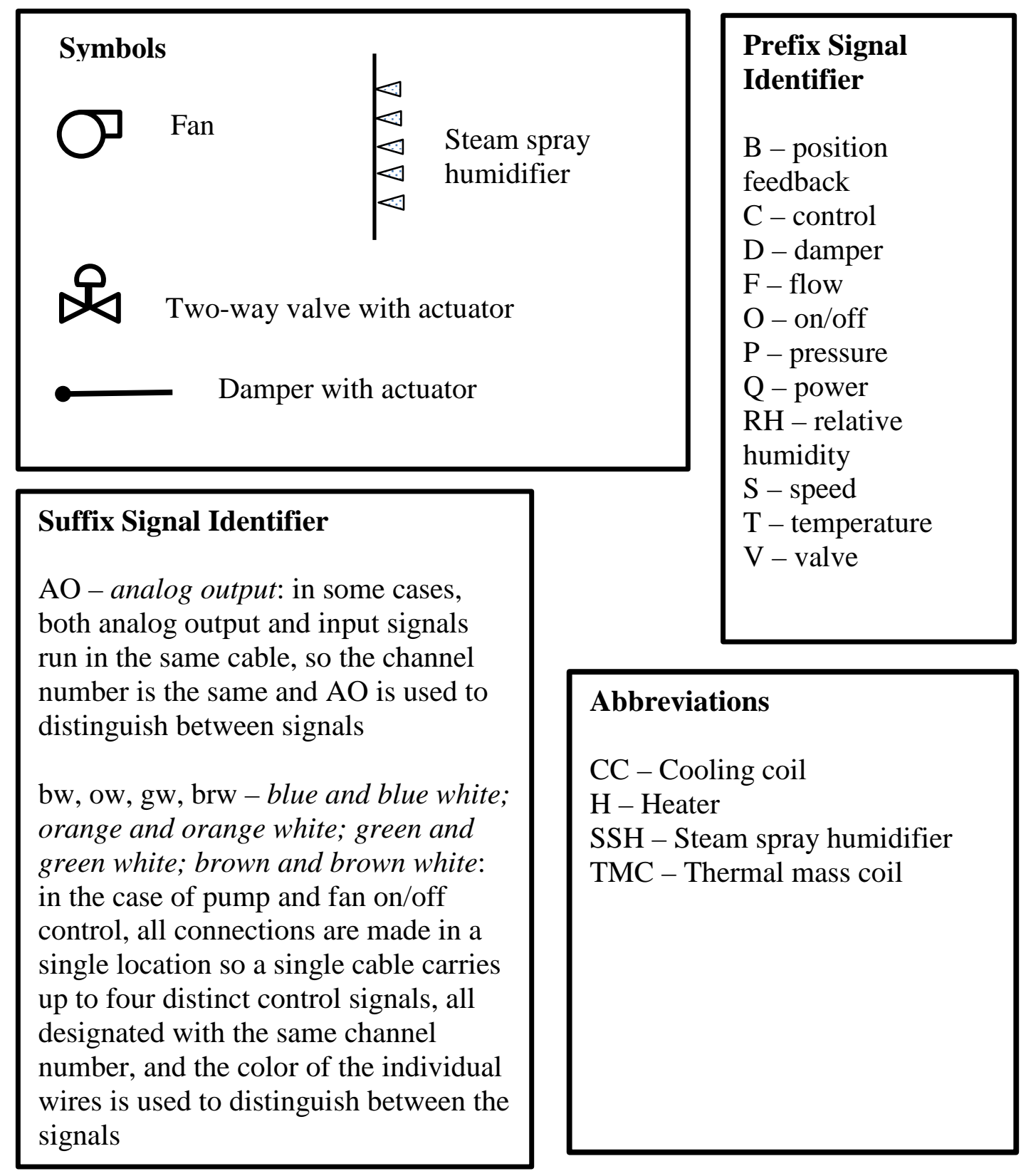

Figure 4. Legend for the component schematics. 
Outside Inside

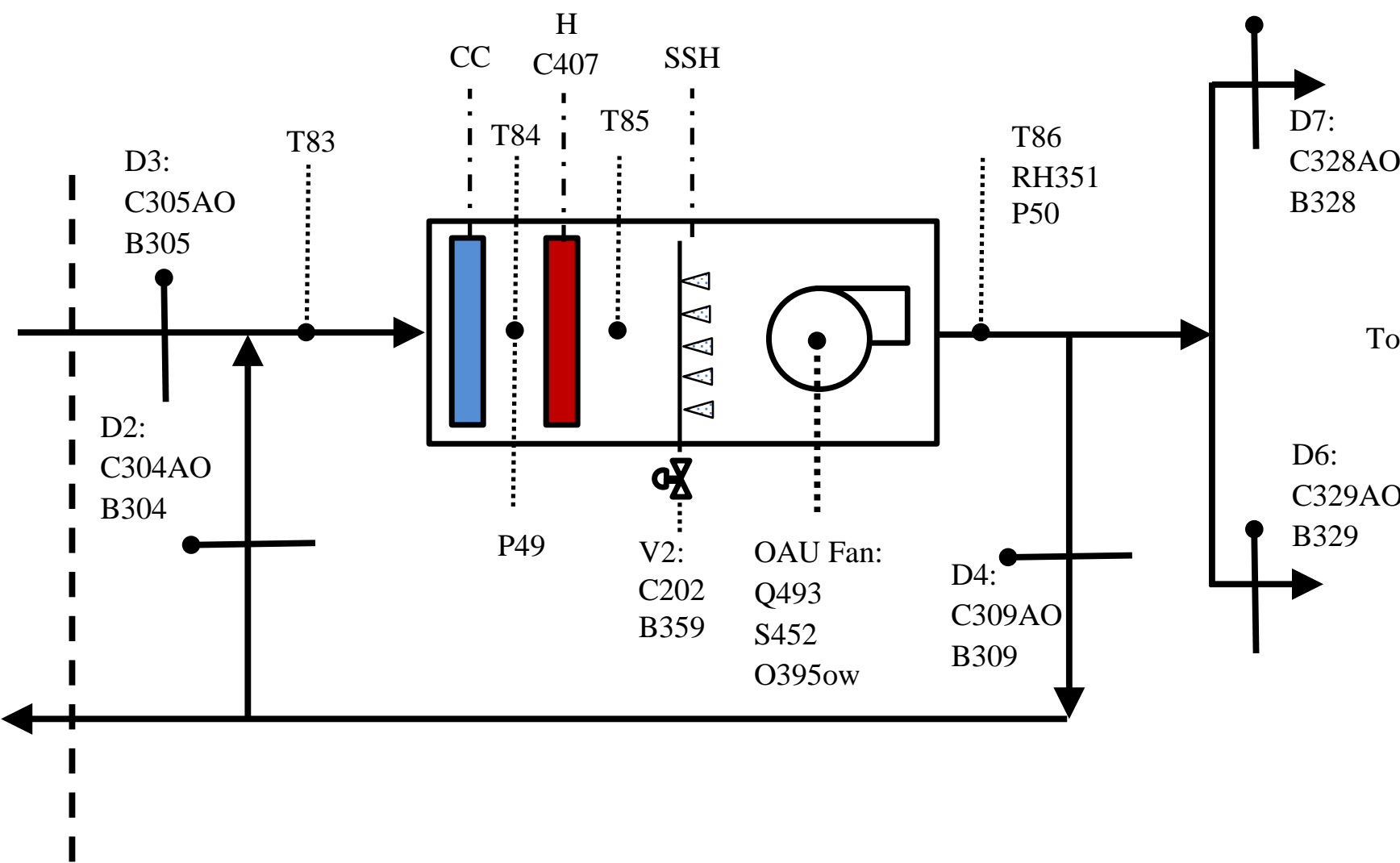

Figure 5. Outdoor air unit (OAU). 


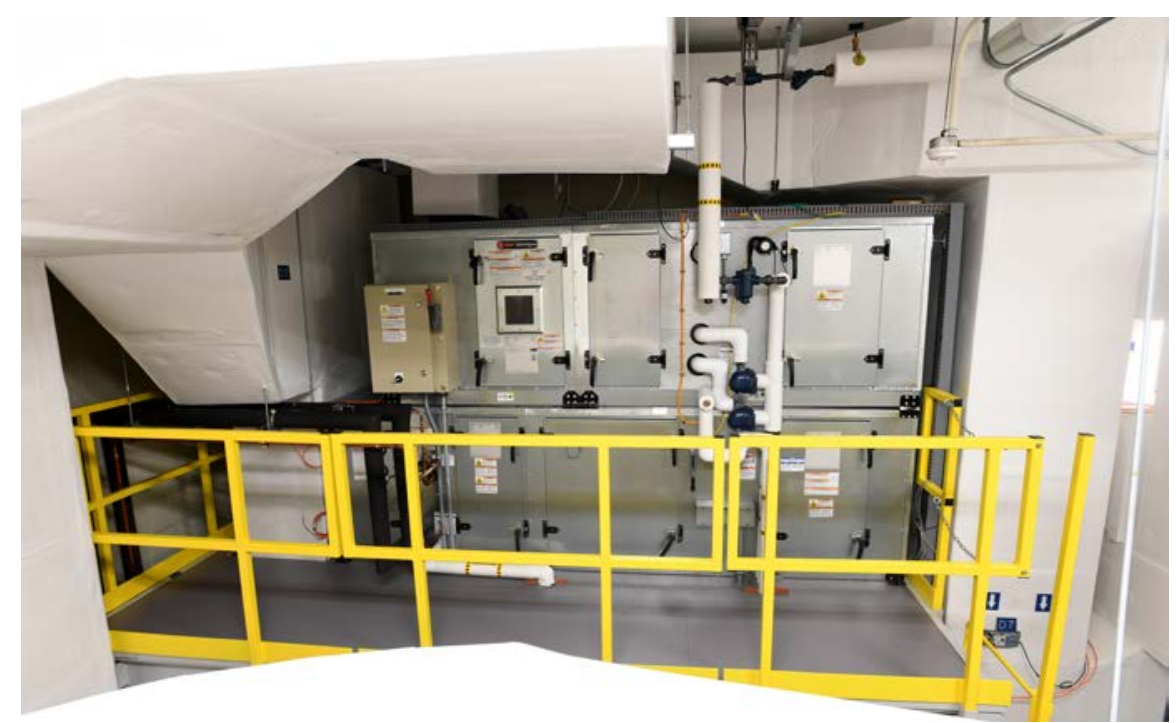

Figure 6. Picture of the OAU. Air is drawn in from the lower left, exits the OAU on the upper left of the unit, and goes to the AHUs at the right (not shown).

\subsection{Air Handling Units}

There are two identical AHUs, shown in Figure 7, each nominally serving two zones. Specifications for the components in the AHUs are given in Table 2. Their arrangement follows an HVAC system design practice described in [4] as "single-duct VAV with reheat," commonly applied to commercial and institutional buildings. The first element of the AHU is electric preheat, which prevents the CC from freezing if the "outside" air is too cold. The CC follows the heater. In the table the design numbers are based on a coolant consisting of 25 \% PG by volume, but once the equipment was in the IBAL the PG percentage was increased to $30 \%$, which affects the heat transfer properties by a small amount. The fan is the last component in the AHU and operates from a VFD. Figure 8 is a picture of the two AHUs.

Table 2. Specifications for the components in the AHU.

\begin{tabular}{l|l|l} 
Component & Description & Value \\
\hline Electric heater & Capacity & $9 \mathrm{~kW}$ \\
& Step controller & $(0$ to 10$) \mathrm{V}$ \\
\hline Cooling coil & Refrigerant & $25 \% \mathrm{PG}$ \\
& Total capacity & $17.6 \mathrm{~kW}(5 \mathrm{tons})$ \\
& Refrigerant design flow & $2 \mathrm{~m}^{3} / \mathrm{h}(9 \mathrm{gpm})$ \\
& Entering dry/wet bulb & $26.7^{\circ} \mathrm{C} / 19.4^{\circ} \mathrm{C}$ \\
& Leaving dry/wet bulb & $12.8^{\circ} \mathrm{C} / 12.7^{\circ} \mathrm{C}$ \\
& Entering PG & $5.6{ }^{\circ} \mathrm{C}$ \\
& Leaving PG & $12.5^{\circ} \mathrm{C}$ \\
\hline Fan & Maximum airflow & $2379 \mathrm{~m} / \mathrm{h}(1400 \mathrm{cfm})$ \\
& Maximum speed & $356 \mathrm{rad} / \mathrm{s}(3396 \mathrm{rpm})$ \\
& Total static pressure & $970 \mathrm{~Pa}\left(3.893 \mathrm{inH} \mathrm{H}_{2} \mathrm{O}\right)$ \\
\hline
\end{tabular}




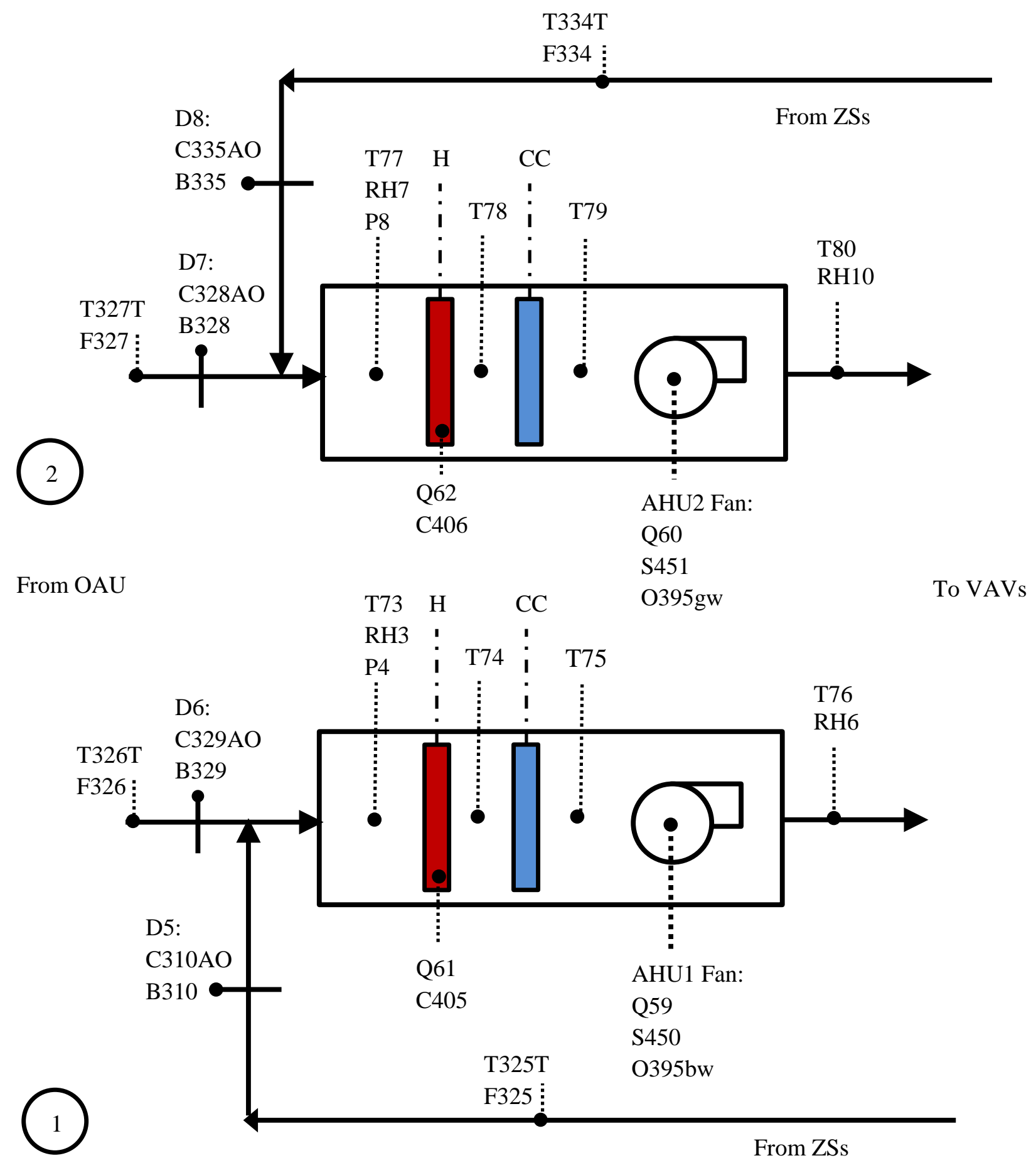

Figure 7. Air Handling Units (AHUs). See Figure 4 for the legend. 


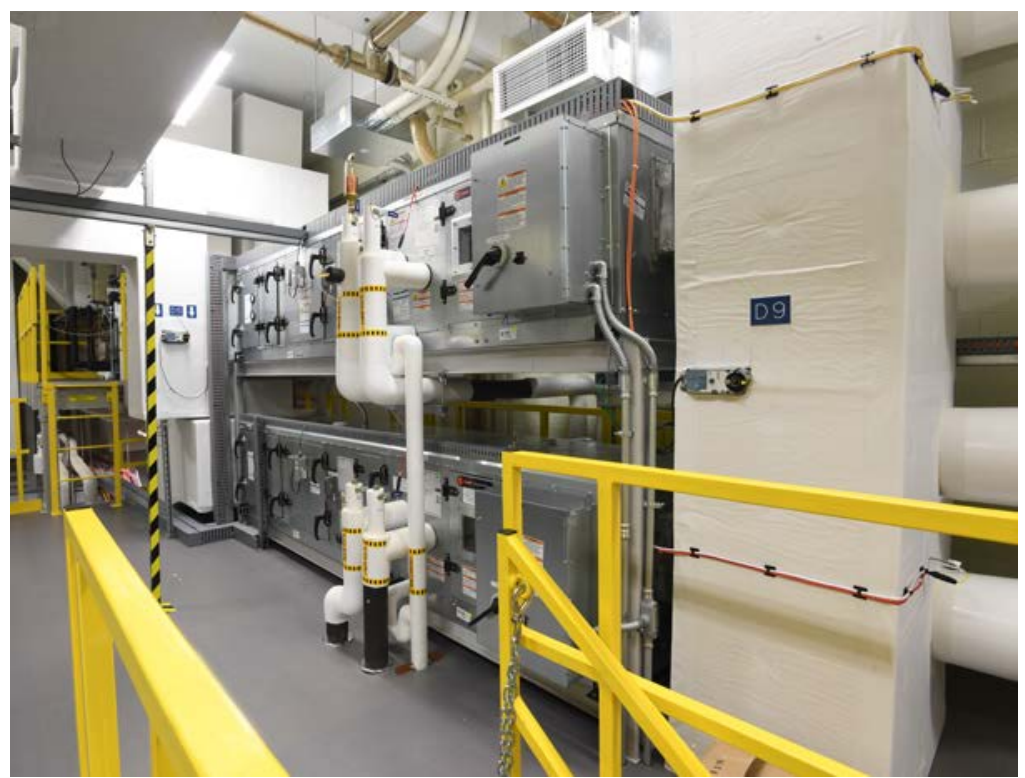

Figure 8. AHU2 (top) and AHU1 (bottom). The OAU is on the upper mezzanine at the far left of the picture and the VAVs, not shown, are to the right.

\subsection{Variable Air Volume Units}

A VAV unit modulates the flowrate of air from an AHU to match the thermal load in the zone it supplies. Having the VAV unit include a "reheat" device allows the same AHU to serve multiple zones even if those zones have very different thermal loads. The IBAL contains four identical VAVs. Each contains a damper for flowrate control and an electric heater for reheat. In a typical control algorithm, the damper is given primary control over zone conditions. If the zone is too cold, the damper will close to reduce the flow of air entering the zone, but if the zone is also "occupied," then ventilation (i.e., fresh air) standards set a lower limit on how much the damper can close. If the damper reaches that limit and the zone is still too cold, the electric heater can be used to reheat the air. The electric heater has a $2 \mathrm{~kW}$ capacity. Figure 9 shows the VAVs and the sensors associated with them and Figure 10 is a picture of the VAVs. 


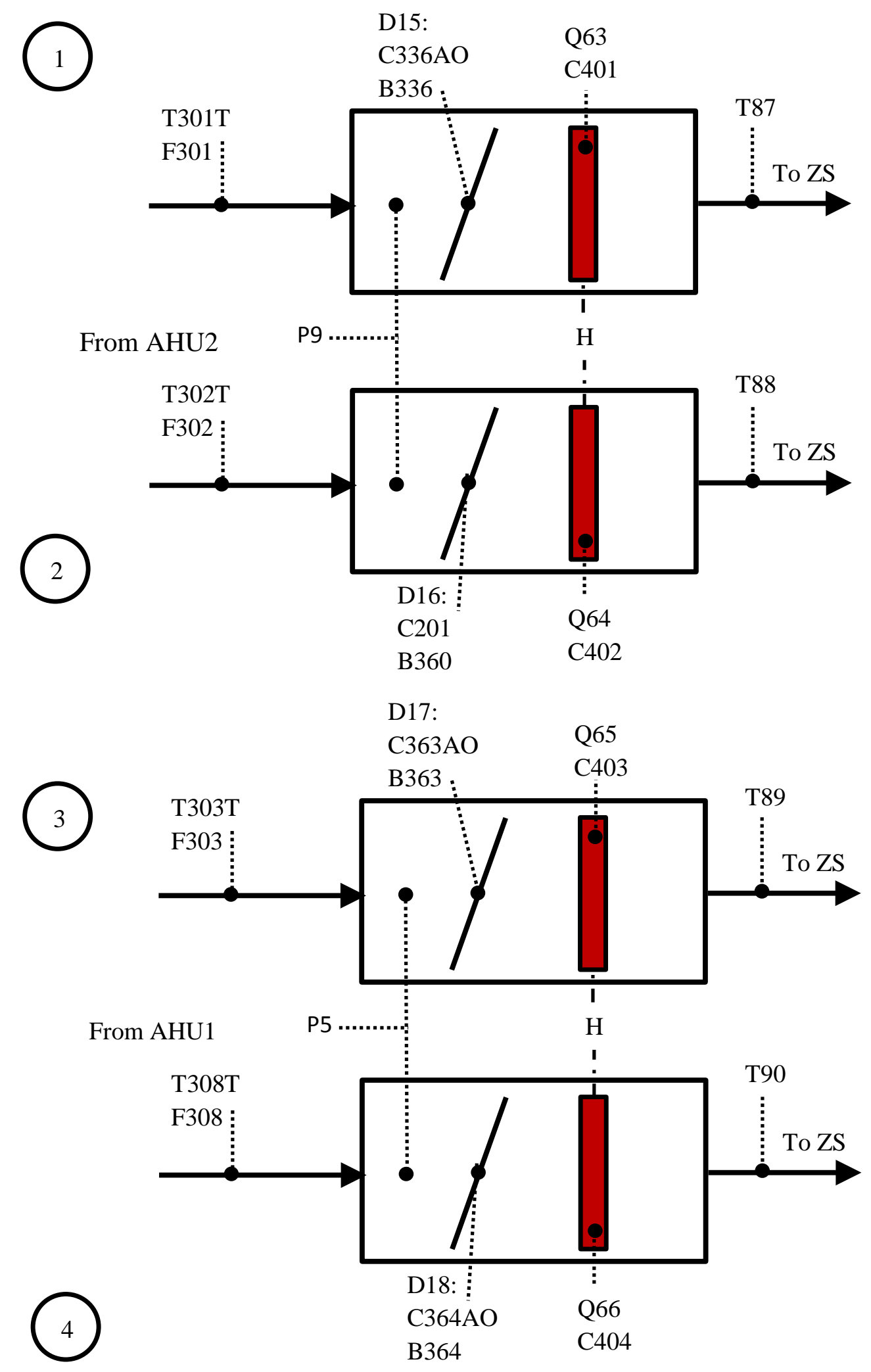

Figure 9. Variable air volume boxes (VAV). See Figure 4 for the legend. 


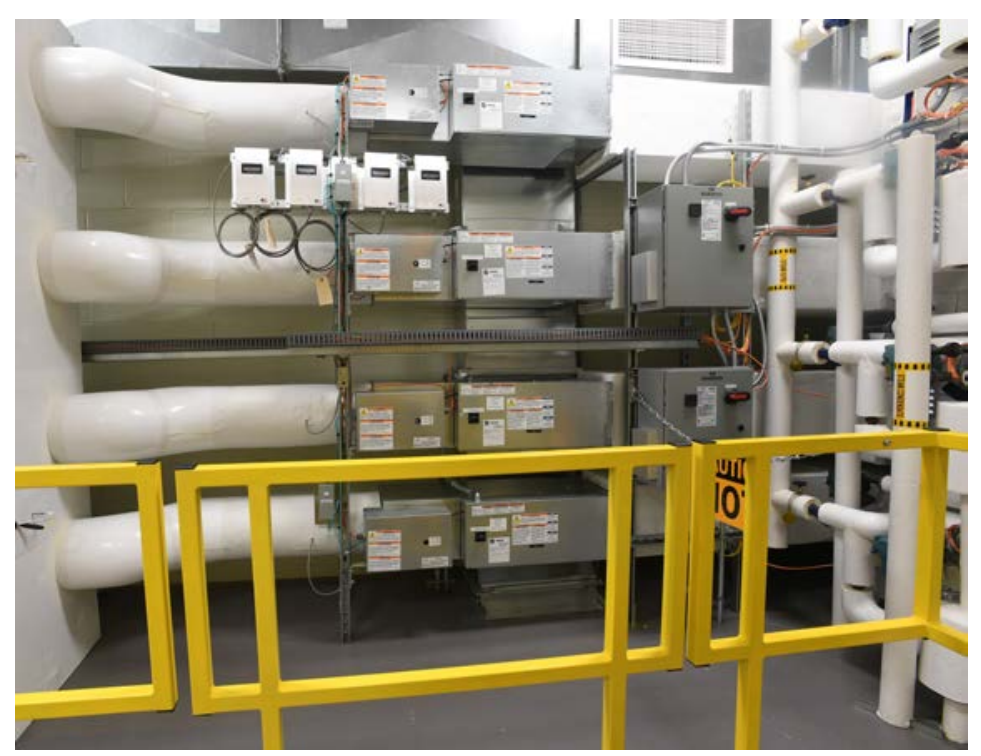

Figure 10. Picture of the VAVs. The AHUs are to the left and the ZSs are to the right.

\subsection{Zone Simulators}

Building HVAC systems are designed based on the expected building loads. The IBAL does not include an actual building or rooms due to space constraints, but zone simulators (ZSs) were designed to provide a load to be met by the HVAC system. There are four ZSs, each containing an electric heater, a SSH, a CC, and a TMC. The electric heater provides the sensible cooling load, the SSH supplies the latent cooling load, the CC provides a heating load, and the TMC provides a source of thermal mass. The focus of the IBAL is to study control systems to meet cooling loads with the underlying belief that the developed methodologies can be adapted to meet heating loads, so the CC is not currently used. Figure $\mathbf{1 1}$ is a schematic of the ZSs. 


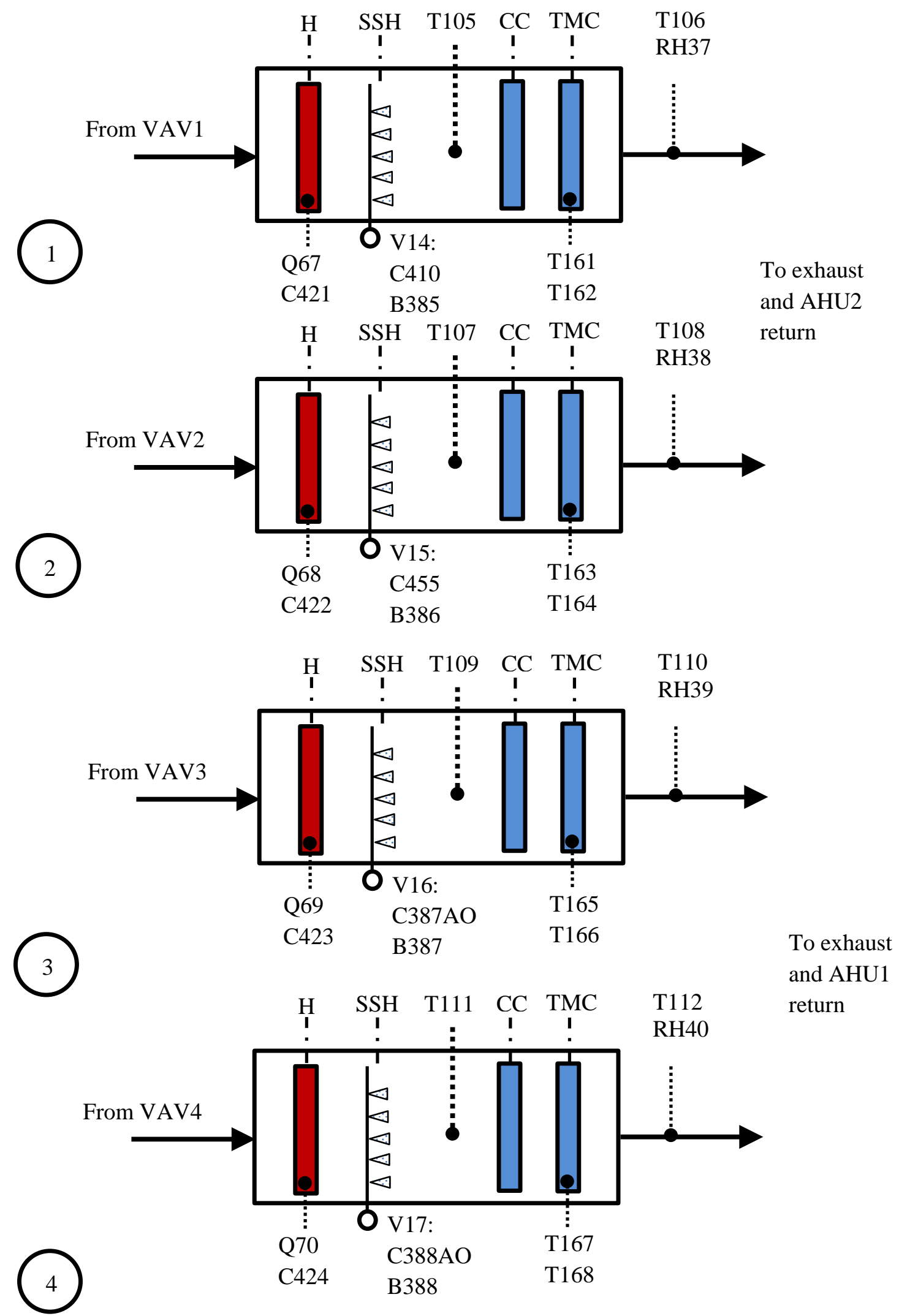

Figure 11. Zone simulators (ZS). See Figure 4 for the legend. 
The four ZSs are stacked one above the other at one end of the mezzanine as shown in Figure 12. Beginning at the far left and moving right are an electric heater, $\mathrm{SSH}$, an access door, a CC, and a TMC (copper pipe runs from the TMC to a water tank). The zone temperature and humidity are measured at the outlet of the $\mathrm{ZS}$.

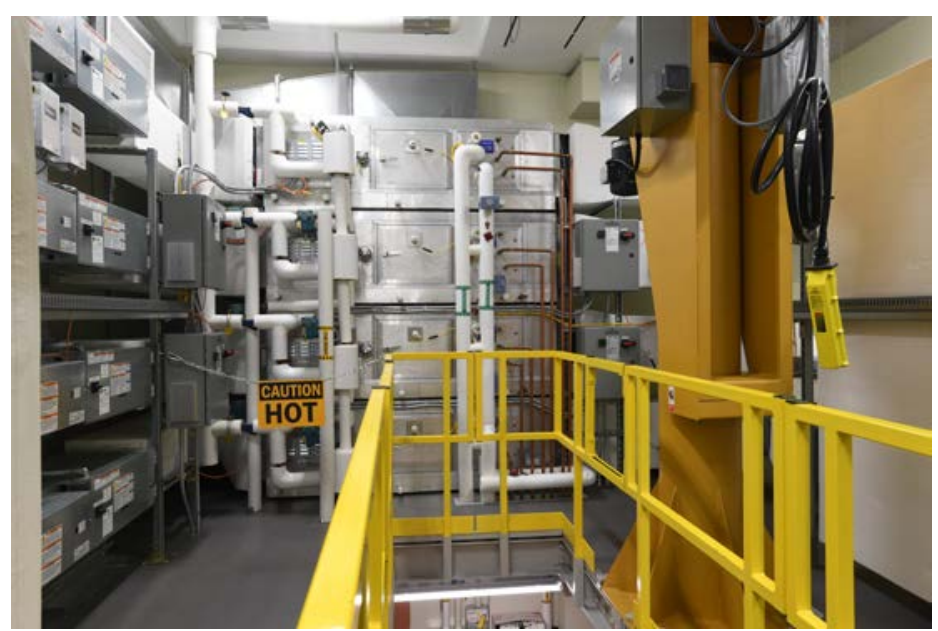

Figure 12. Picture of the four ZSs. The VAVs are at the left.

Each ZS was designed to represent a $65 \mathrm{~m}^{2}\left(700 \mathrm{ft}^{2}\right)$ room in an office building and the equipment within the ZS was sized to provide the loads defined by each of two cases: (1) open office space and (2) conference room. The magnitude of the loads in both cases are based on the tables in the ASHRAE Handbook of Fundamentals [5]. For Case 1, there are six occupants, each performing office work. The room has a $32.5 \mathrm{~m}^{2}\left(350 \mathrm{ft}^{2}\right)$ exterior wall with $7 \mathrm{~m}^{2}\left(75 \mathrm{ft}^{2}\right)$ of glass facing southwest, and the magnitude of the heat gain through the envelope is based on conditions in Maryland. A summary of the loads for this zone is provided in Table 3. The sensible load is provided by the electric heater and the latent load is provided by the $\mathrm{SSH}$.

Table 3. Loads for Case 1: open office space.

\begin{tabular}{|l|l|l|l|}
\hline Source & Type of Load & Load & Total Load \\
\hline \multirow{2}{*}{ Person } & Sensible heat & $72 \mathrm{~W}(245 \mathrm{BTU} / \mathrm{h})$ & $430 \mathrm{~W}(1470 \mathrm{BTU} / \mathrm{h})$ \\
\cline { 2 - 4 } & Latent heat load & $60 \mathrm{~W}(205 \mathrm{BTU} / \mathrm{h})$ & $360.5 \mathrm{~W}(1230 \mathrm{BTU} / \mathrm{h})$ \\
\hline Equipment & Workstation & $175 \mathrm{~W}(597 \mathrm{BTU} / \mathrm{h})$ & $1050 \mathrm{~W}(3583 \mathrm{BTU} / \mathrm{h})$ \\
\hline Lighting & Lighting & $11.8 \mathrm{~W} / \mathrm{m}^{2}\left(1.1 \mathrm{~W} / \mathrm{ft}^{2}\right)$ & $770 \mathrm{~W}(2627 \mathrm{BTU} / \mathrm{h})$ \\
\hline Envelope & Heat gain & $2344 \mathrm{~W}(8000 \mathrm{BTU} / \mathrm{h})$ & $2344 \mathrm{~W}(8000 \mathrm{BTU} / \mathrm{h})$ \\
\hline \multicolumn{2}{|l}{} & Total & $4955 \mathrm{~W}(16,910 \mathrm{BTU} / \mathrm{h})$ \\
\hline
\end{tabular}

For Case 2 (see Table 4) there are 18 people performing office work in the conference room. There is one projector and one workstation and the envelope is the same as in Case 1. 
Table 4. Loads for Case 2: conference room.

\begin{tabular}{|l|l|l|l|}
\hline Source & Type of Load & Load & Total Load \\
\hline \multirow{2}{*}{ Person } & Sensible heat & $72 \mathrm{~W}(245 \mathrm{BTU} / \mathrm{h})$ & $1292 \mathrm{~W}(4410 \mathrm{BTU} / \mathrm{h})$ \\
\cline { 2 - 4 } & Latent heat load & $60 \mathrm{~W}(205 \mathrm{BTU} / \mathrm{h})$ & $1081 \mathrm{~W}(3690 \mathrm{BTU} / \mathrm{h})$ \\
\hline Equipment & Workstation + projector & $500 \mathrm{~W}(1706 \mathrm{BTU} / \mathrm{h})$ & $500 \mathrm{~W}(1706 \mathrm{BTU} / \mathrm{h})$ \\
\hline Lighting & Lighting & $11.8 \mathrm{~W} / \mathrm{m}^{2}\left(1.1 \mathrm{~W} / \mathrm{ft}^{2}\right)$ & $770 \mathrm{~W}(2627 \mathrm{BTU} / \mathrm{h})$ \\
\hline Envelope & Heat gain & $2344 \mathrm{~W}(8000 \mathrm{BTU} / \mathrm{h})$ & $2344 \mathrm{~W}(8000 \mathrm{BTU} / \mathrm{h})$ \\
\hline & Total & $5987 \mathrm{~W}(20,433 \mathrm{BTU} / \mathrm{h})$ \\
\hline
\end{tabular}

The electric heater and SSH were selected to meet either of these two cases as a minimum, but the ZS operation will not be limited to these scenarios. Table 5 shows the specifications for the key components in the ZS and the required level of operation for each of the cases.

Table 5. Specifications for the components in the ZSs.

\begin{tabular}{|c|c|c|c|c|}
\hline Component & Description & Value & Case 1 & Case 2 \\
\hline \multirow{2}{*}{ Electric heater } & $\begin{array}{l}\text { Capacity } \\
{ }^{1} \text { SCR controller }\end{array}$ & $\begin{array}{l}5 \mathrm{~kW} \\
(0 \text { to } 10) \mathrm{V}\end{array}$ & $4.59 \mathrm{~kW}$ & $4.9 \mathrm{~kW}$ \\
\hline & Minimum airflow & $\begin{array}{l}187 \mathrm{~m}^{3} / \mathrm{h} \\
(110 \mathrm{cfm})\end{array}$ & & \\
\hline \multirow{2}{*}{$\begin{array}{l}\text { Steam spray } \\
\text { humidifier }\end{array}$} & Steam pressure & $\begin{array}{l}34.5 \mathrm{kPa} \\
\text { (15 psig) }\end{array}$ & & \\
\hline & Steam rate & $\begin{array}{l}1.8 \mathrm{~kg} / \mathrm{h} \\
(4 \mathrm{lbm} / \mathrm{h})\end{array}$ & $\begin{array}{l}0.6 \mathrm{~kg} / \mathrm{h} \\
(1.25 \mathrm{lbm} / \mathrm{h})\end{array}$ & $\begin{array}{l}1.8 \mathrm{~kg} / \mathrm{h} \\
(4 \mathrm{lbm} / \mathrm{h})\end{array}$ \\
\hline
\end{tabular}

${ }^{1}$ Silicon-controlled rectifier

The electric heater and SSH provide a means to simulate the cooling loads in a zone, but a real zone also has thermal mass that acts to damp out changes in the temperature of the zone. For example, in a real room if an additional person (additional load) enters the room, the room temperature does not immediately increase. If there is no equivalent thermal mass in the ZS, an increase in the heater level will lead to an immediate change in temperature. The TMC is designed to provide the ZS with a means to damp out temperature changes. It was sized to mimic the effect of adding an occupant and workstation to the zone such that the temperature of the room would rise by $0.56{ }^{\circ} \mathrm{C}\left(1{ }^{\circ} \mathrm{F}\right)$ in $120 \mathrm{~s}$. The volume of water required to achieve this effect is calculated as shown in Eq. ( 1 ). To achieve the desired effect, a water volume of $13 \mathrm{~L}$ (3.35 gal) is required. 


$$
\begin{gathered}
\text { Volume }\left[\mathrm{m}^{3}\right]=\frac{Q[\mathrm{~kW}] \mathrm{t}[\mathrm{s}]}{c_{p}[\mathrm{~kJ} / \mathrm{kg}-\mathrm{K}] \Delta T[\mathrm{~K}] \rho\left[\mathrm{kg} / \mathrm{m}^{3}\right]} \\
Q=72+175=247 \mathrm{~W} \\
t=120 \mathrm{~s} \\
c_{p}=4.18 \mathrm{~kJ} / \mathrm{kg}-\mathrm{K} \\
\Delta T=0.56 \mathrm{~K} \\
\rho=998 \mathrm{~kg} / \mathrm{m}^{3}
\end{gathered}
$$

Rather than just placing a container of water in each ZS that will heat up over time, fluid circulates through the TMC so that at any given moment there is a volume of water in the TMC, but since it is not stagnant it has an opportunity to release heat outside of the ZS. Each TMC is independently supplied by a $76 \mathrm{~L}$ (20-gallon) water tank with a dedicated circulating pump. The flow rate of the water through the coil will be adjusted to achieve the desired effect. Figure 13 shows the water tanks and circulating pumps that supply the TMC.

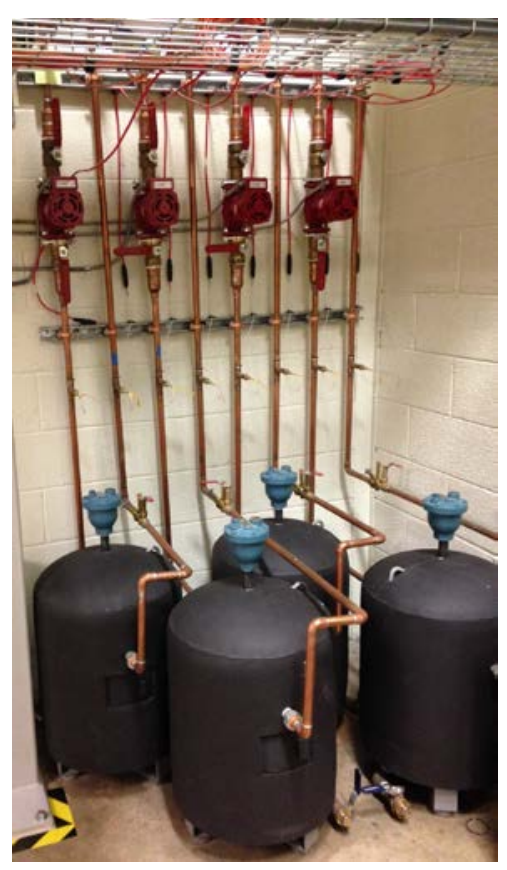

Figure 13. The black tanks hold water for the thermal mass coils in the zone simulators. Above the tanks are the red circulating pumps that move the water through the TMCs. The flow rate is determined by manually setting a valve.

The four zone simulators together can generate a sensible load of $20 \mathrm{~kW}$ (5.7 ton) and a latent load of approximately $4.3 \mathrm{~kW}$ (1.2 ton), for a total load of $24 \mathrm{~kW}$ (6.9 ton). 


\subsection{Exhaust Fans}

The IBAL contains two identical exhaust fans that push air outside. Table 6 contains the specifications for the fans.

Table 6. Specifications for the exhaust fans.

\begin{tabular}{l|l|l} 
Component & Description & Value \\
\hline Fan & Maximum airflow & $2379 \mathrm{~m}^{3} / \mathrm{h}(1400 \mathrm{cfm})$ \\
& Maximum speed & $226 \mathrm{rad} / \mathrm{s}(2156 \mathrm{rpm})$ \\
& Total static pressure & $249 \mathrm{~Pa}\left(1 \mathrm{inH}_{2} \mathrm{O}\right)$ \\
\hline
\end{tabular}

\subsection{Data Collection and Operation}

The data acquisition system (DAQ) was described in detail in Technical Note 1933, Sec. 4 [3]. The air system uses the same equipment and control software approach.

\section{Measurement Uncertainty Calculations}

This section provides an overview of the calibration curve fits for the air pressure and relative humidity (RH) measurements. Sections. 3.1 and 3.2 are reproduced, and updated as appropriate, from Pertzborn [3]. The Appendix contains detailed calculations; the results presented in this section are shown with fewer significant digits.

\subsection{Overview}

According to Taylor and Kuyatt [6], uncertainty is categorized as one of two types, Type A or Type B. Type A uncertainties are determined from a statistical evaluation of data, such as calculating standard deviation from a series of independent measurements. Uncertainty calculated from calibration data is an example of Type A. Type B uncertainties are based on scientific judgement and prior data, such as manufacturer specifications. When there is more than one source of uncertainty, they are summed in quadrature as shown in Eq. ( 2 ).

$$
u_{\text {total }}=\sqrt{u_{1}^{2}+u_{2}^{2}+\cdots+u_{n}^{2}}
$$

Table 7 contains the measurement uncertainties of the hardware in the DAQ. These values are included in the total uncertainty calculation. AI uncertainty is the uncertainty of an analog input channel and $A O$ uncertainty is the uncertainty of an analog output channel. 
Table 7. Uncertainties of temperature, voltage, and current measurements of DAQ hardware.

\begin{tabular}{|c|c|c|c|c|}
\hline Card & AI uncertainty & Units & AO uncertainty & Units \\
\hline 4357 & 0.126 & ${ }^{\circ} \mathrm{C}$ & & \\
\hline 4300 & 0.002460 & $\mathrm{~V}$ & & $\mathrm{~A}$ \\
\hline 6238 & 0.0000188 & $\mathrm{~A}$ & 0.0000523 & $\mathrm{~V}$ \\
\hline 6363 & 0.00166 & $\mathrm{~V}$ & 0.00189 & $\mathrm{~V}$ \\
\hline \multirow{2}{*}{6704} & & & 0.00107 & $\mathrm{~A}$ \\
\cline { 2 - 5 } & & & 0.000000448 & $\mathrm{~V}$ \\
\hline 6345 & 0.001520 & $\mathrm{~V}$ & 0.00189 & \\
\hline
\end{tabular}

\subsection{Uncertainty of Calibration Curve Fit}

This section contains the equations used to calculate the uncertainty of the curve fit derived from calibration data that relates the measured voltage signal to the engineering units of the sensor. For example, the pressure transducers in the air system output a current signal that is converted to voltage at the DAQ by dropping it across a $249 \Omega$ resistor, the voltage is measured by card 4300, and then converted to $\mathrm{inH}_{2} \mathrm{O}$. The relationship between the measured signal and engineering units is linear. During calibration, pressure or relative humidity is the independent $x$ variable, while voltage is the dependent $y$ variable. Eq. ( 3 ) shows the relationship between the dependent and independent variables, where the slope $m$ and intercept $b$ are found from the calibration data as shown in Eqs. ( 4 ) and ( 5 ) [7].

$$
\begin{gathered}
y=m x+b \\
m=\frac{S_{x y}}{S_{x x}} \\
b=\bar{y}-m \bar{x} \\
\bar{x}=\frac{\sum_{i=1}^{n} x_{i}}{n} \\
S_{x y}=\sum x_{i} y_{i}-\frac{\sum x_{i} \sum y_{i}}{n}=\sum\left(x_{i}-\bar{x}\right)\left(y_{i}-\bar{y}\right) \\
S_{x x}=\sum x_{i}^{2}-\frac{\left(\sum x_{i}\right)^{2}}{n}=\sum\left(x_{i}-\bar{x}\right)^{2}
\end{gathered}
$$

The standard error of the calibration is determined from the fit by first calculating the residual $y_{r}$ between the fit $\hat{y}$ and the measured $y$ as shown in Eqs. ( 9 ) and ( 10 ). 


$$
\begin{gathered}
\hat{y}=m x+b \\
y_{r}=y-\hat{y}
\end{gathered}
$$

The standard error, $s e$, is calculated by dividing the sum of the squares of the residuals, SSResid, by the number of degrees of freedom, $v$, and taking the square root. The expanded standard error, $s e_{e}$, which is the $95 \%$ confidence interval, is calculated by multiplying the $s e$ by the $t$ statistic that corresponds to the degrees of freedom. See Eqs. ( 11 ) through ( 14 ). This final error is the calibration uncertainty.

$$
\begin{gathered}
\text { SSResid }=\sum_{i=1}^{n} y_{r_{i}}^{2} \\
v=n-2 \\
s e=\sqrt{\frac{\text { SSResid }}{v}} \\
s e_{e}=t \cdot s e
\end{gathered}
$$

In order to apply the calibration curve fit to experimental data, in which voltage is now the independent variable, the relationship defined by Eq. ( 3 ) has to be rewritten as shown in Eq. ( 15 ) to solve for the engineering units.

$$
x=\frac{y-b}{m}
$$

The slope and intercept that are part of the metadata defined for each channel, $a_{1}$ and $a_{0}$, respectively, are derived from Eq. ( 15 ) and shown in Eq. ( 16 ). The scaling is applied as shown in Eq. ( 17 ), in which $x$ is the final scaled value and $y$ is the measured value.

$$
\begin{gathered}
a_{0}=-\frac{b}{m}, \quad a_{1}=\frac{1}{m} \\
x=a_{0}+a_{1} y
\end{gathered}
$$

The uncertainty also has to be scaled, but prior to scaling any additional measurement uncertainties, such as the DAQ measurement uncertainty from Table 7 and the uncertainty in the calibration standard, have to be included as shown in Eq. ( 18 ). The final scaled uncertainty is shown in Eq. ( 19 ).

$$
\begin{gathered}
u=\sqrt{s e_{e}^{2}+u_{\text {other }}^{2}} \\
u_{\text {total }}=\frac{u}{m}
\end{gathered}
$$




\subsection{Pressure Transducers}

In the IBAL duct air pressure is measured in ten locations using capacitance sensors. The sensors output a current signal (mA) that is proportional to the pressure. That current is passed through a $249 \Omega$ resistor and the voltage across this resistor is read by card 4300 . The pressure sensors have two uses: 1) monitor fan performance and 2) provide a controller input. In the former case, a pressure measurement is made both upstream and downstream of a fan to monitor the static pressure generated by the fan. Changes in that measurement over time can indicate if there are problems with a fan. In the latter case, the pressure measurement is used by the control system to change fan speed in response to a change in the duct static pressure. For example, if a VAV damper closes because the zone needs less airflow, the duct static pressure will increase, and the control system can decrease the fan speed so that it delivers less air to the VAV. This type of operation decreases the fan energy consumption. In both cases, the absolute accuracy of the measurement is not the key, the accuracy of the measurement of changes in the pressure from one time to another is the key.

The calibration was performed using a precision pressure controller with a (0 to 2491) $\mathrm{Pa}$ ( $(0$ to 10$) \mathrm{inH}_{2} \mathrm{O}$ ) pressure regulator. The uncertainty of the reference standard is $74.7 \mathrm{~Pa}$ $\left(0.003 \mathrm{inH}_{2} \mathrm{O}\right)$. The calibration does not address the pitot tube-pressure transducer system, but just the pressure transducer accuracy. Figure 14 shows the calibration setup and Table 8 shows the results.

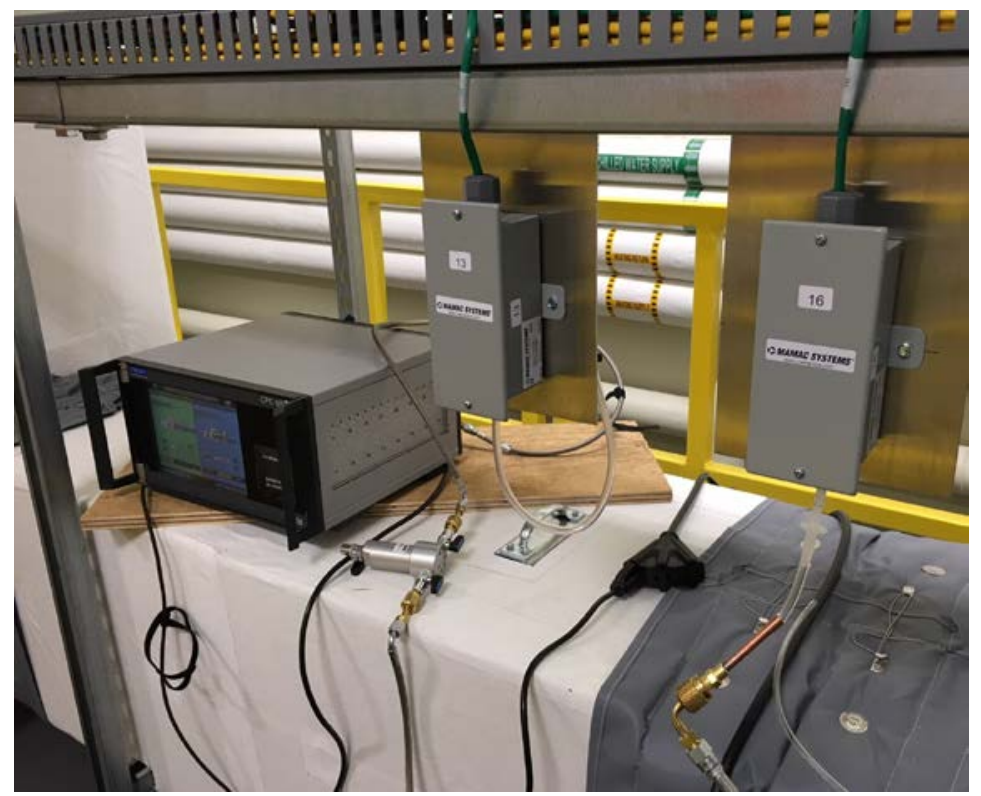

Figure 14. Picture of the air pressure calibration setup. The precision pressure controller is at the far left and two pressure transducers (the gray boxes) are visible.

For channels 4, 8, and 49 the calibration covered (0 to 124.5) Pa because the transducer is linear with pressure and a vacuum supply was unavailable for the negative range. The other channels were calibrated over the full range. In all cases the order in which calibration pressures were applied to the transducer was randomly determined. At least 40 data points were acquired at each pressure setting. 
Table 8. Air pressure transducer uncertainty results.

\begin{tabular}{|c|c|c|c|c|}
\hline Channel Number & $\begin{array}{c}\text { Range [Pa] } \\
\text { (inH } \mathbf{O})\end{array}$ & $\mathbf{a}_{0}[\mathbf{P a}]\left(\mathbf{i n H}_{2} \mathbf{O}\right)$ & $\mathbf{a}_{1}[\mathbf{P a} / \mathbf{V}]\left(\mathbf{i n H} \mathbf{H}_{2} \mathbf{O} / \mathbf{V}\right)$ & $\mathbf{u}_{\text {total }}[\mathbf{P a}]$ (inH $\left.\mathbf{O}\right)$ \\
\hline 4 & $\begin{array}{c}-124.5 \text { to } 124.5 \\
(-0.5 \text { to } 0.5)\end{array}$ & $-193.4(-0.777)$ & $62.8(0.252)$ & $1.84(0.008)$ \\
\hline 5 & 0 to $249(0$ to 1$)$ & $-64.2(-0.258)$ & $62.2(0.250)$ & $0.93(0.004)$ \\
\hline 8 & $\begin{array}{c}-124.5 \text { to } 124.5 \\
(-0.5 \text { to } 0.5)\end{array}$ & $-192.7(-0.774)$ & $61.8(0.248)$ & $1.26(0.005)$ \\
\hline 9 & 0 to $249(0$ to 1$)$ & $-67.7(-0.272)$ & $62(0.249)$ & $0.79(0.004)$ \\
\hline 13 & 0 to $249(0$ to 1$)$ & $-68.8(-0.276)$ & $62.5(0.251)$ & $0.82(0.004)$ \\
\hline 14 & 0 to $249(0$ to 1$)$ & $-66(-0.265)$ & $62(0.249)$ & $0.83(0.004)$ \\
\hline 16 & 0 to $249(0$ to 1$)$ & $-65.6(-0.263)$ & $62.3(0.25)$ & $0.89(0.004)$ \\
\hline 17 & 0 to $249(0$ to 1$)$ & $-69.6(-0.279)$ & $62.3(0.25)$ & $0.90(0.004)$ \\
\hline 49 & $\begin{array}{c}-124.5 \text { to } 124.5 \\
(-0.5 \text { to } 0.5)\end{array}$ & $-192.5(-0.773)$ & $61.4(0.247)$ & $1.45(0.006)$ \\
\hline 50 & 0 to $249(0$ to 1$)$ & $-68.1(-0.274)$ & $62.3(0.25)$ & $0.89(0.004)$ \\
\hline
\end{tabular}

\subsection{Airflow Sensors}

The airflow sensors use thermal dispersion technology to measure both airflow and temperature. The sensor is factory calibrated to a NIST-traceable standard and the manufacturer recommends not calibrating the system in-situ. Therefore, the uncertainty for these sensors is a combination of the manufacturer specified uncertainty and the DAQ card uncertainty. The airflow sensors output two (4 to 20) $\mathrm{mA}$ signals that are converted to voltage by passing each of them through a $249 \Omega$ resistor and then reading the voltage across the resistor using card 6363 .

Table 9. Measurement uncertainty of airflow sensors.

\begin{tabular}{|c|c|c|}
\hline Measurement & $\begin{array}{c}\text { Manufacturer } \\
\text { Uncertainty }\end{array}$ & $\begin{array}{c}\text { Card } \\
\text { Uncertainty }\end{array}$ \\
\hline Airflow & $\pm 2 \%$ of reading & $0.00166 \mathrm{~V}$ \\
\hline Temperature & $\pm 0.08^{\circ} \mathrm{C}\left(0.15^{\circ} \mathrm{F}\right)$ & $0.00166 \mathrm{~V}$ \\
\hline
\end{tabular}

The conversions from voltage to engineering units for the various airflow sensors are provided in Table 10.

Table 10. Measurement uncertainty of airflow sensors.

\begin{tabular}{|c|c|c|}
\hline Channel Number & $\mathbf{a}_{0}$ & $\mathbf{a}_{1}$ \\
\hline $301-303,308$ & $-739.6 \mathrm{~m}^{3} / \mathrm{h}(-435.31 \mathrm{cfm})$ & $742.6 \mathrm{~m}^{3} / \mathrm{h} / \mathrm{V}(437.06 \mathrm{cfm} / \mathrm{V})$ \\
\hline $306-307,325-327,334$ & $-3761 \mathrm{~m}^{3} / \mathrm{h}(-2213.89 \mathrm{cfm})$ & $3777 \mathrm{~m}^{3} / \mathrm{h}(2222.78 \mathrm{cfm} / \mathrm{V})$ \\
\hline $\begin{array}{c}301 \mathrm{~T}-303 \mathrm{~T}, 306 \mathrm{~T}-308 \mathrm{~T}, \\
325 \mathrm{~T}-327 \mathrm{~T}, 334 \mathrm{~T}\end{array}$ & $-35.99^{\circ} \mathrm{C}\left(-64.78{ }^{\circ} \mathrm{F}\right)$ & $24.98^{\circ} \mathrm{C} / \mathrm{V}\left(44.96{ }^{\circ} \mathrm{F} / \mathrm{V}\right)$ \\
\hline
\end{tabular}




\subsection{Relative Humidity Sensors}

The RH sensors use a capacitive sensing element to measure RH. The sensors output a (4 to 20) mA signal that is converted to voltage at the DAQ across a $249 \Omega$ resistor. The humidity sensors were calibrated using the Air-Conditioner and Heat Pump Test Chamber at NIST [8]. The sensors were installed in a section of duct and calibrated against a dewpoint sensor with an uncertainty of $0.25^{\circ} \mathrm{C}$. This uncertainty is much lower than the uncertainty of the calibration fit. The results of the calibration are given in Table 11.

Table 11. Measurement uncertainty and calibration fit for RH sensors.

\begin{tabular}{|c|c|c|c|}
\hline Channel Number & $\mathbf{a}_{\mathbf{0}}[\mathbf{\%}]$ & $\begin{array}{c}\mathbf{a}_{\mathbf{1}} \\
{[\mathbf{\%} / \mathbf{V}]}\end{array}$ & $\begin{array}{c}\mathbf{u}_{\text {total }} \\
{[\mathbf{\%}]}\end{array}$ \\
\hline 3 & -20.19 & 24.62 & 0.84 \\
\hline 6 & -19.43 & 23.83 & 1.02 \\
\hline 7 & -19.4 & 24.26 & 1 \\
\hline 10 & -19.91 & 24.35 & 0.96 \\
\hline 37 & -20.45 & 24.69 & 0.89 \\
\hline 38 & -20.28 & 24.68 & 0.89 \\
\hline 39 & -19.39 & 24.18 & 1.06 \\
\hline 40 & -19.98 & 24.32 & 0.98 \\
\hline 51 & -20.31 & 24.13 & 0.91 \\
\hline
\end{tabular}

\section{Summary and Future Work}

This paper described the design of the air system, including the equipment and measurement uncertainty of some of the key instrumentation. Additional measurement uncertainty calculations will be detailed in a future technical note. The schematics showed the location of measurements and the channel numbers corresponding to those measurements. The IBAL as it stands to date has now been described in full.

Work will continue to develop the software to automate the operation of the IBAL and link the air system with the hydronic system. Future publications will detail the control and characteristics of subsystems such as the OAU. The major focus will be on the development of intelligent control algorithms for the operation of the facility. 


\section{References}

[1] US Energy Information Administration, “U.S. energy flow, 2017,” 2017. [Online]. Available: https://www.eia.gov/totalenergy/data/monthly/pdf/flow/total_energy.pdf. [Accessed: 06-Sep-2018].

[2] G. E. Kelly and S. T. Bushby, "Are intelligent agents the key to optimizing building HVAC system performance?,” HVAC R Res., vol. 18, no. 4, pp. 750-759, 2012.

[3] A. J. Pertzborn, "NIST Technical Note 1933: Intelligent Building Agents Laboratory: Hydronic System Design,” 2016.

[4] H. G. Lorsch, Air-Conditioning Systems Design Manual. American Society of Heating, Refrigerating and Air-Conditioning Engineers, 1993.

[5] ASHRAE, ASHRAE handbook of fundamentals. Atlanta: Atlanta: American Society of Heating, Air-Conditioning and Refrigeration Engineers, Inc., 2009.

[6] B. N. Taylor and C. E. Kuyatt, "NIST Technical Note 1297: Guidelines for Evaluating and Expressing the Uncertainty of NIST Measurement Results,” 1994.

[7] J. Devore and N. Farnum, Applied Statistics for Engineers and Scientists, 2nd ed. Belmont, CA: Thomson Brooks/Cole, 2005.

[8] NIST, “HVAC\& R Equipment Environmental Chambers | NIST.” [Online]. Available: https://www.nist.gov/laboratories/tools-instruments/hvacr-equipment-environmentalchambers. [Accessed: 13-Sep-2018]. 


\section{Appendix}

This Appendix contains a list of the sensors in the air system with part numbers (Table 12) and data for the uncertainty calculations (Table 13 and Table 14).

Table 12. Summary of sensors in the air system in the IBAL.

\begin{tabular}{|c|c|c|c|}
\hline Sensor & Channel Number & $\mathbf{P} / \mathbf{N}$ & $\mathbf{S} / \mathbf{N}$ \\
\hline \multirow{10}{*}{ Pressure } & 4 & Mamac PR274-R2-MA & \\
\hline & 5 & Mamac PR274-R2-MA & \\
\hline & 8 & Mamac PR274-R2-MA & \\
\hline & 9 & Mamac PR274-R2-MA & \\
\hline & 13 & Mamac PR274-R2-MA & \\
\hline & 14 & Mamac PR274-R2-MA & \\
\hline & 16 & Mamac PR274-R2-MA & \\
\hline & 17 & Mamac PR274-R2-MA & \\
\hline & 49 & Mamac PR274-R2-MA & \\
\hline & 50 & Mamac PR274-R2-MA & \\
\hline \multirow{9}{*}{$\begin{array}{l}\text { Relative } \\
\text { Humidity }\end{array}$} & 3 & ACI A/RH2-100-R2 & \\
\hline & 6 & ACI A/RH2-100-R2 & \\
\hline & 7 & ACI A/RH2-100-R2 & \\
\hline & 10 & ACI A/RH2-100-R2 & \\
\hline & 37 & ACI A/RH2-100-R2 & \\
\hline & 38 & ACI A/RH2-100-R2 & \\
\hline & 39 & ACI A/RH2-100-R2 & \\
\hline & 40 & ACI A/RH2-100-R2 & \\
\hline & 51 & ACI A/RH2-100-R2 & \\
\hline \multirow{10}{*}{$\begin{array}{l}\text { Airflow and } \\
\text { Temperature }\end{array}$} & $301,301 \mathrm{~T}$ & Ebtron GTC116-P+1/2 & 708322 \\
\hline & $302,302 \mathrm{~T}$ & Ebtron GTC116-P+1/2 & 708558 \\
\hline & $303,303 \mathrm{~T}$ & Ebtron GTC116-P+1/2 & 708564 \\
\hline & $306,306 \mathrm{~T}$ & Ebtron GTC116-P+1/2 & 708432 \\
\hline & $307,307 \mathrm{~T}$ & Ebtron GTC116-P+1/2 & 708422 \\
\hline & $308,308 \mathrm{~T}$ & Ebtron GTC116-P+1/2 & 708554 \\
\hline & $325,325 \mathrm{~T}$ & Ebtron GTC116-P+1/2 & 708439 \\
\hline & $326,326 \mathrm{~T}$ & Ebtron GTC116-P+1/2 & 707957 \\
\hline & $327,327 \mathrm{~T}$ & Ebtron GTC116-P+1/2 & 708382 \\
\hline & $334,334 \mathrm{~T}$ & Ebtron GTC116-P+1/2 & 708329 \\
\hline
\end{tabular}


Table 13. Calibration data for pressure transducers.

\begin{tabular}{|c|c|c|c|c|c|c|c|c|c|c|c|c|c|c|c|}
\hline $\begin{array}{l}\text { Channel } \\
\text { Number }\end{array}$ & $\mathbf{n}$ & $\begin{array}{c}\bar{x} \\
{\left[\mathrm{inH}_{2} \mathrm{O}\right]}\end{array}$ & $\begin{array}{c}\bar{y} \\
{[\mathrm{~V}]}\end{array}$ & $\begin{array}{c}S_{x y} \\
{\left[i n H_{2} O-V\right]}\end{array}$ & $\begin{array}{c}\mathbf{S}_{\mathrm{xx}} \\
{\left[\mathrm{inH}_{2} \mathbf{O}^{2}\right]}\end{array}$ & $\begin{array}{c}\mathbf{M} \\
{\left[\mathrm{V} / \mathbf{i n H}_{2} \mathbf{O}\right]}\end{array}$ & $\begin{array}{c}\mathbf{b} \\
{[\mathbf{V}]}\end{array}$ & $\begin{array}{c}\text { SSResid } \\
\text { [V] }\end{array}$ & $v$ & se $[\mathrm{V}]$ & $\mathbf{t}$ & $\begin{array}{c}\mathbf{a}_{0} \\
{\left[\mathrm{inH}_{2} \mathrm{O}\right]}\end{array}$ & $\begin{array}{c}\mathbf{a}_{1} \\
{\left[\operatorname{inH}_{2} \mathrm{O} / \mathrm{V}\right]}\end{array}$ & $\begin{array}{l}\mathbf{t} \text { *se*a1 } \\
{\left[\mathrm{inH}_{2} \mathrm{O}\right]}\end{array}$ & $\begin{array}{c}\mathbf{u}_{\text {total }} \\
{\left[\mathrm{inH}_{2} \mathrm{O}\right]}\end{array}$ \\
\hline 5 & 11 & 0.50 & 3.03 & 4.36 & 1.09 & 4.01 & 1.03 & 0.00013 & 9 & 0.004 & 2.26 & -0.258 & 0.250 & 0.0021 & 0.0037 \\
\hline 9 & 11 & 0.50 & 3.11 & 4.36 & 1.09 & 4.02 & 1.09 & 0.00002 & 9 & 0.002 & 2.26 & -0.272 & 0.249 & 0.0009 & 0.0032 \\
\hline 13 & 11 & 0.50 & 3.10 & 4.39 & 1.10 & 3.99 & 1.10 & 0.00004 & 9 & 0.002 & 2.26 & -0.276 & 0.251 & 0.0012 & 0.0033 \\
\hline 14 & 11 & 0.50 & 3.06 & 4.39 & 1.09 & 4.02 & 1.06 & 0.00005 & 9 & 0.002 & 2.26 & -0.265 & 0.249 & 0.0013 & 0.0033 \\
\hline 17 & 8 & 0.43 & 2.84 & 4.18 & 1.04 & 4.00 & 1.12 & 0.00006 & 6 & 0.003 & 2.45 & -0.279 & 0.250 & 0.0020 & 0.0036 \\
\hline 49 & 11 & 0.25 & 4.15 & 1.12 & 0.27 & 4.06 & 3.14 & 0.00070 & 9 & 0.009 & 2.26 & -0.773 & 0.247 & 0.0049 & 0.0058 \\
\hline
\end{tabular}

Table 14. Calibration data for relative humidity sensors.

\begin{tabular}{|c|c|c|c|c|c|c|c|c|c|c|c|c|c|c|c|}
\hline $\begin{array}{l}\text { Channel } \\
\text { Number }\end{array}$ & $\mathbf{n}$ & $\bar{x}[\%]$ & $\bar{y}[\mathrm{~V}]$ & $S_{x y}[\%-V]$ & $\mathrm{S}_{\mathrm{xx}}\left[\%^{2}\right]$ & m [V/\%] & b [V] & $\begin{array}{c}\text { SSResid } \\
\text { [V] }\end{array}$ & $v$ & se [V] & $\mathbf{t}$ & $\mathbf{a}_{0}[\%]$ & $\begin{array}{c}\mathrm{a}_{1} \\
{[\% / \mathrm{V}]}\end{array}$ & $\begin{array}{c}\text { t*se*a1 } \\
{[\%]}\end{array}$ & $\begin{array}{l}\text { Utotal } \\
{[\%]}\end{array}$ \\
\hline 3 & 572270 & 63.42 & 3.40 & 863155 & 21250410 & 0.04 & 0.82 & 173.57 & 572268 & 0.017 & 1.96 & -20.19 & 24.62 & 0.84 & 0.84 \\
\hline 6 & 572270 & 63.42 & 3.48 & 891888 & 21250410 & 0.04 & 0.82 & 274.58 & 572268 & 0.022 & 1.96 & -19.43 & 23.83 & 1.02 & 1.02 \\
\hline 7 & 572270 & 63.42 & 3.41 & 876049 & 21250410 & 0.04 & 0.80 & 254.17 & 572268 & 0.021 & 1.96 & -19.40 & 24.26 & 1.00 & 1.00 \\
\hline 10 & 572270 & 63.42 & 3.42 & 872752 & 21250410 & 0.04 & 0.82 & 232.21 & 572268 & 0.020 & 1.96 & -19.91 & 24.35 & 0.96 & 0.96 \\
\hline 37 & 572270 & 63.42 & 3.40 & 860814 & 21250410 & 0.04 & 0.83 & 191.34 & 572268 & 0.018 & 1.96 & -20.45 & 24.69 & 0.88 & 0.89 \\
\hline 38 & 572270 & 63.42 & 3.39 & 860866 & 21250410 & 0.04 & 0.82 & 190.96 & 572268 & 0.018 & 1.96 & -20.28 & 24.68 & 0.88 & 0.89 \\
\hline 39 & 572270 & 63.42 & 3.42 & 878713 & 21250410 & 0.04 & 0.80 & 286.73 & 572268 & 0.022 & 1.96 & -19.39 & 24.18 & 1.06 & 1.06 \\
\hline 40 & 572270 & 63.42 & 3.43 & 873788 & 21250410 & 0.04 & 0.82 & 242.45 & 572268 & 0.021 & 1.96 & -19.98 & 24.32 & 0.98 & 0.98 \\
\hline 51 & 572270 & 63.42 & 3.47 & 880820 & 21250410 & 0.04 & 0.84 & 212.27 & 572268 & 0.019 & 1.96 & -20.31 & 24.13 & 0.91 & 0.91 \\
\hline
\end{tabular}

